\title{
Flexural properties of three kinds of experimental fiber-reinforced composite posts
}

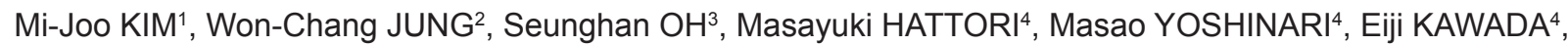 \\ Yutaka ODA ${ }^{4}$ and Ji-Myung BAE ${ }^{3}$
}

\author{
${ }^{1}$ Department of Dental Biomaterials and Bioengineering, Dental College, Yonsei University, 250 Seongsanno, Seodaemun-gu, Seoul 120-752, Korea \\ ${ }^{2}$ Giheung-gu Health Center, 352-3 Gugal-dong, Giheung-gu, Yongin, Gyeonggi-do 446-593, Korea \\ ${ }^{3}$ Department of Dental Biomaterials, Dental College, Wonkwang University, 344-2 Sinyong-dong, Iksan 570-749, Korea \\ ${ }^{4}$ Department of Dental Materials Science, Tokyo Dental College, 1-2-2 Masago, Mihama-ku, Chiba 261-8502, Japan \\ Corresponding author, Ji-Myung BAE; E-mail: baejimy@wku.ac.kr
}

\begin{abstract}
The aim of this study was to estimate the flexural properties of three kinds of experimental fiber-reinforced composite (FRC) posts and to evaluate their potential use as posts. Experimental FRC posts were fabricated with glass, aramid, and UHMWP fibers. Commercial FRC posts were used for comparison. A three-point bending test was performed at a crosshead speed of $1 \mathrm{~mm} / \mathrm{min}$. Experimental glass fiber posts showed significantly higher flexural strengths and moduli than aramid and UHMWP posts. Experimental UHMWP posts demonstrated superior toughness to the commercial posts. The glass fiber posts displayed stiff, strong and brittle features, while the UHMWP posts were flexible, weak and ductile. The flexural properties of the aramid posts fell between those of the glass and UHMWP posts. In conclusion, the glass fiber posts proved excellent in flexural strengths and moduli. However, the superior toughness of UHMWP fibers suggests the possibility of their use as posts in combination with glass fibers.
\end{abstract}

Keywords: Fiber-reinforced composite (FRC), Post, Flexural properties

\section{INTRODUCTION}

It has been well documented that dental posts play an important role in retaining a core when endodontic treatment for supporting a crown is inevitably coupled with insufficient dentin ${ }^{1)}$. There are two types of posts currently in use: custom-made cast posts and prefabricated posts. According to the composition, prefabricated posts are divided into metal (stainless steel, nickel chromium alloy and titanium alloy), ceramic, and fiber-reinforced composite (FRC) posts ${ }^{2}$. Metal posts have been used mainly in restorative dentistry for many years, and non-metal posts such as FRC and ceramic posts have been popular in clinical practice ${ }^{3,4)}$. FRC posts show lower rates of root fracture than do metal posts, as their elastic moduli are similar to those of dentin ${ }^{5,6}$. In addition, FRC posts have superior adhesive strengths with resin cements and esthetic properties compared to metal posts ${ }^{7,8)}$. Although ceramic posts show high compressive properties, they have the disadvantage of brittleness. When above threshold stress is applied to ceramic posts, they are prone to fracture rather than distributing the load ${ }^{9,10}$. Zirconia posts, in particular, are difficult to etch, rendering them difficult to bond with a resin core $^{11)}$. In addition, retrieving ceramic posts is extremely difficult when endodontic re-treatment is necessary ${ }^{3,12)}$.

FRC is a composite material with embedded fibers within a resin matrix ${ }^{13)}$. The fibers used in FRC are primarily glass, quartz, carbon, polyaromatic polyamide (aramid), and ultra high molecular weight polyethylene

Color figures can be viewed in the online issue, which is available at J-STAGE

Received Apr 21, 2010: Accepted Aug 30, 2010

doi:10.4012/dmj.2010-053 JOI JST.JSTAGE/dmj/2010-053
(UHMWP) ${ }^{14)}$. Glass fibers have been incorporated within the fields of automotive, marine and flooring industries; aramid fibers are utilized in ballistic products such as bullet-proof vests, armor, sporting goods, tires, ropes and cables ${ }^{15,16)}$. UHMWP fibers have been investigated as a reinforcement element of dentures, fixed orthodontic retainers, space maintainers, post-traumatic stabilizing splints, fixed partial dentures, and direct use as posts ${ }^{17-20)}$. The mechanical properties of FRC are dependent upon: (1) the component, architecture (unidirectional, bidirectional, or woven), and geometric orientation of the fibers, (2) the component of the resin matrix, (3) the ratio of fiber to resin matrix, and (4) the adhesion between the fibers and resin matrix ${ }^{13,21-23)}$. The resin matrix used in FRC posts are either epoxy resin or other polymers having a high degree of conversion and a highly cross-linked structure ${ }^{24)}$. Semi-interpenetrating polymer network (IPN) can also be used as a resin matrix to enhance the adhesion between FRC posts and luting resin cements ${ }^{25-27)}$.

Previous studies of FRC posts mainly focused on prefabricated FRC posts composed of glass or quartz $\mathrm{z}^{24,28-30)}$. However, the type of resin matrices and the fiber contents of prefabricated FRC posts differed, making comparisons of absolute results impossible. Therefore, controlling the factors affecting the mechanical properties of various FRC posts is required. In addition, it is necessary to assess the characteristics of alternative fiber posts, other than glass or quartz fibers, such as aramid and UHMWP, to evaluate their potential use as posts.

In this study, resin matrices and experimental FRC posts composed of glass, aramid and UHMWP were 
fabricated by controlling the amount and the orientation of fibers. The objective of this study was to determine the flexural properties of each experimental glass, aramid and UHMWP FRC post, and to compare them with various commercial FRC posts in order to evaluate their potential use as posts. The null hypothesis of this study projected that the flexural properties of three experimental FRC posts, with identical volume percentages, do not differ, regardless of the type of fibers.

\section{MATERIALS AND METHODS}

The resin matrix of experimental FRC posts was fabricated with bisphenol-A-glycidyl dimethacrylate (NK Oligo, EMA-1020) containing an inhibitor of methoxyhydroquinone (100 ppm/kg), urethane dimethacrylate, triethylene glycol dimethacrylate, camphorquinone, and dimethylaminoethyl methacrylate.
Detailed information of the resin matrix components is listed in Table 1.

Three types of fibers were used to reinforce the fabricated resin matrix (Table 2). Glass fibers (ER $270 \mathrm{FW})$ were $13 \mu \mathrm{m}$ in diameter and $270 \mathrm{TEX}(\mathrm{g} / \mathrm{km})$ E-glass, treated with a silane-coupling agent. The aramid fibers (Kevlar 29) had a $14 \mu \mathrm{m}$ diameter and 1,500 denier, without surface treatment. The UHMWP fibers (Ribbond) had a woven structure with a $23 \mu \mathrm{m}$ diameter and $2 \mathrm{~mm}$ width of a ribbon treated with a cold gas plasma ${ }^{18,31)}$. The density of each fiber was measured by a density determination kit (YDK 01, Sartorius AG, Goettingen, Germany) attached to a balance (CP224S, Sartorius AG).

The commercial FRC posts used for comparison were $70 \mathrm{v} / \mathrm{v} \%$ glass fiber posts (FRC Postec Plus), $60 \mathrm{v} / \mathrm{v} \%$ glass fiber posts (Parapost Fiber Lux), and $60 \mathrm{v} / \mathrm{v} \%$ quartz fiber posts (DT Light Post) (Table 3).

Table 1 Components of the resin matrix fabricated in this study

\begin{tabular}{lllr}
\hline Component & \multicolumn{1}{c}{ Chemical } & \multicolumn{1}{c}{ Manufacturer } & Content (weight \%) \\
\hline Dimethacrylate & $*$ Bis-GMA & Shin-Nakamura Chemical Co., Ltd., & 53.1 \\
Dimethacrylate & $* *$ WDMA & Aldrich, MO, USA & 17.7 \\
Dimethacrylate & \#TEGDMA & Aldrich, MO, USA & 26.5 \\
Photosensitizer & Camphorquinone & Aldrich, MO, USA & 0.9 \\
Amine initiator & \#DMAEMA & Aldrich, MO, USA & 1.8 \\
\hline
\end{tabular}

* Bis-GMA: bisphenol-A-glycidyl dimethacrylate

**UDMA: urethane dimethacrylate

\#TEGDMA: triethylene glycol dimethacrylate

\#\#DMEMA: dimethylaminoethyl methacrylate

Table 2 Three types of fibers used to fabricate fiber-reinforced composite posts, and their density measurements

\begin{tabular}{lcllc}
\hline Fiber & Code & Brand name & \multicolumn{1}{c}{ Manufacturer } & $\begin{array}{c}\text { Density } \\
\left(\mathrm{g} / \mathrm{cm}^{3}\right)\end{array}$ \\
\hline Glass & GA & ER 270FW & $\begin{array}{l}\text { Hankuk Fiber Co., LTD, } \\
\text { Milyang, Korea }\end{array}$ & $\begin{array}{c}2.41 \\
(0.15)^{*}\end{array}$ \\
$\begin{array}{l}\text { Polyaromatic polyamide } \\
\text { (Aramid) }\end{array}$ & PA & Kevlar 29 & DuPont Co., Inc., & 1.36 \\
$\begin{array}{l}\text { Ultra high molecular weight } \\
\text { polyethylene (UHMWP) }\end{array}$ & PE & Ribbond & Ribbond Inc., & $(0.06)$ \\
\hline
\end{tabular}

* Standard deviation of measured density is in parenthesis.

Table 3 Commercial fiber-reinforced composite posts used for the comparison

\begin{tabular}{llll}
\hline Brand name & DT Light Post & FRC Postec Plus & Parapost Fiber Lux \\
\hline Code & DT & Postec & ParaLux \\
Manufacturer & Bisco, & Ivoclar/Vivadent, & Coltene/Whaledent, \\
& Schaumburg, USA & Liechtenstein & France \\
Component & Quartz & Glass & Glass \\
(Volume \%) & $(60)$ & $(70)$ & $(60)$ \\
Shape & Tapered & Tapered & Paralleled \\
Diameter $(\mathrm{mm})$ & 1.5 & 1.5 & 1.5 \\
\hline
\end{tabular}




\section{Resin matrix fabrication}

To fabricate the resin matrix, each component was weighed in a $100 \mathrm{~mL}$ borosilicate glass bottle (SCHOTTDURAN, Mitterteich, Germany) wrapped with aluminum foil to protect against irradiation using a balance (CP224S, Sartorius) with the accuracy of $0.0001 \mathrm{~g}$. The components were mixed in the bottle and capped with an air-tight polytetrafluoroethylene plug coupled with an overhead stirrer (RW20DZM.n, IKA-WERKE Gmbh \& Co. KG, Staufen, Germany) for 30 minutes. During mixing, the temperature was maintained at $40^{\circ} \mathrm{C}$ by use of a hot plate (RCH-3, Tokyo Rikakikai Co., Ltd., Tokyo, Japan) in order to enhance the homogenization of the mixed sample. Air bubbles in the mixed sample were removed by a vacuum pump for 1 hour.

\section{Fiber-reinforced composite post fabrication}

For the fabrication of the experimental FRC posts, 60 and $75 \mathrm{v} / \mathrm{v} \%$ of glass fibers (GA60 and GA75), $60 \mathrm{v} / \mathrm{v} \%$ of aramid fibers (PA60) and $60 \mathrm{v} / \mathrm{v} \%$ of UHMWP fibers (PE60) were calculated from their density and weight (See Table 2). The weighed fibers, according to their corresponding percentages, were inserted into a flexible plastic tube (TYGON ${ }^{\circledR}$ R-3603 Laboratory tubing, SaintGobain, Ohio, USA) with an internal diameter of 1.5 $\mathrm{mm}$. The fabricated resin matrix was then gradually injected into the plastic tube using a $20 \mathrm{~mL}$ syringe. The open ends of each tube were polymerized by the irradiation of a LED light curing unit (Elipar FreeLight 2, 3M, Seefeld, Germany) for 20 seconds. The plastic tube was then fixed in a putty mold in order to maintain the experimental FRC posts straight. After the plastic tube with the putty mold was polymerized by using a laboratory light-curing unit (Visio Beta Vario, 3M) for 21 minutes, the tube was peeled off. Fig. 1 displays the four types of experimental fiber posts and the commercial FRC posts.

\section{Three-point bending test}

A three point bending test was performed using a universal testing machine (Z020, Zwick, Ulm, Germany) to measure the flexural strength, modulus and toughness of the fabricated resin matrix, the experimental FRC posts, and the commercial FRC posts. The crosshead speed was $1 \mathrm{~mm} / \mathrm{min}$, and the span of the two supports was $10 \mathrm{~mm}$. The fracture load was determined by the load dropped down $30 \%$ from the maximum load. In the case of the tapered posts (FRC Postec Plus and DT Light Post), only the parallel portions were positioned on the supports. The sample size of the resin matrix, and each experimental FRC post group was 10; that of each commercial FRC post group was 5. The stress-strain curves were also evaluated.

\section{Scanning electron microscopy (SEM)}

After loading, the longitudinal and the cross-section of each experimental post were observed by a scanning electron microscope (JSM-6360, Jeol Ltd., Tokyo, Japan). For a cross-sectional view, the fractured part of each post was sectioned and embedded in acrylic resin (OrthoJet,

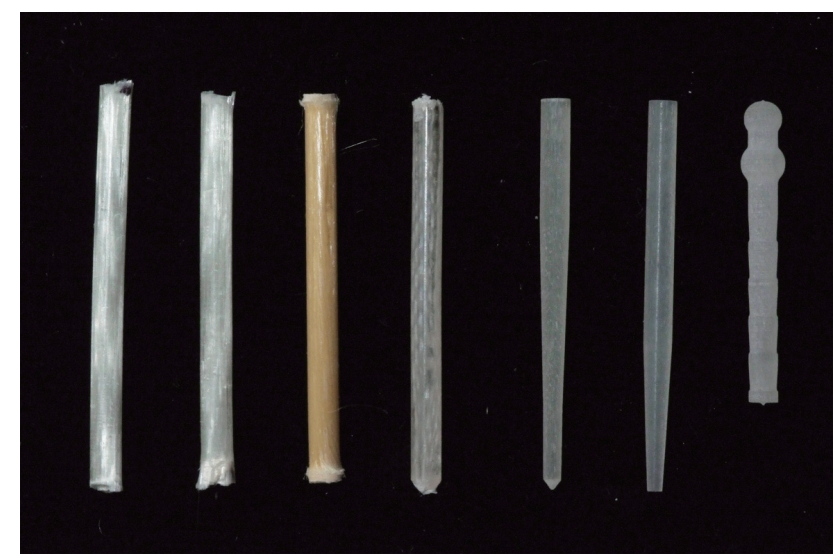

Fig. 1 The posts with the diameter of $1.5 \mathrm{~mm}$ used for the study: four experimental FRC posts (GA60, GA75, PA60, and PE60), and three commercial FRC posts (DT Light Post, FRC Postec Plus, and Parapost Fiber Lux) shown from left to right.

Lang dental, OH, USA) with the sectioned surface exposed. The surface was then polished with a series of abrasive papers (180, 320, 600, and 1,000 grits) followed by a pan cloth with $5 \mu \mathrm{m}$ aluminum oxide and a suede cloth with $0.3 \mu \mathrm{m}$ aluminum oxide.

\section{Statistical analysis}

The statistical analysis for the flexural strength, modulus and toughness was conducted using a Kruskal-Wallis test and the Duncan's multiple range test by using a SPSS (version 12, Statistical Package for Social Science, SPSS Inc., Chicago, IL, USA) ( $\alpha=0.05)$.

\section{RESULTS}

Flexural properties of experimental and commercial FRC posts

The flexural strength of the resin matrix was increased significantly by all three experimental fibers as shown in Fig. $2(p<0.05)$. Among the experimental FRC posts, both the GA60 and GA75 posts showed higher flexural strengths than did the PA60 and PE60 posts $(p<0.05)$. The flexural strengths of both the GA60 and GA75 posts were not significantly different from those of commercial FRC posts $(p>0.05)$.

The flexural moduli of the experimental FRC posts were in the following order: GA75 $>$ GA60 $>$ PA60 $>$ PE60 $(p<0.05)$ (Fig. 3). The flexural modulus of GA75 was significantly higher than the commercial FRC posts $(p<0.05)$.

The toughness of PE 60 were significantly higher than GA $75(p<0.05)$. The toughness of GA 75, GA 60 and PE60 were significantly higher than the commercial FRC posts $(p<0.05)$ (Fig. 4).

The stress-strain curves of several posts clearly revealed their flexural characteristics (Fig. 5). The GA post was stiff, strong, and brittle, while the PE post was flexible, weak, and ductile. The PA post was weak and 


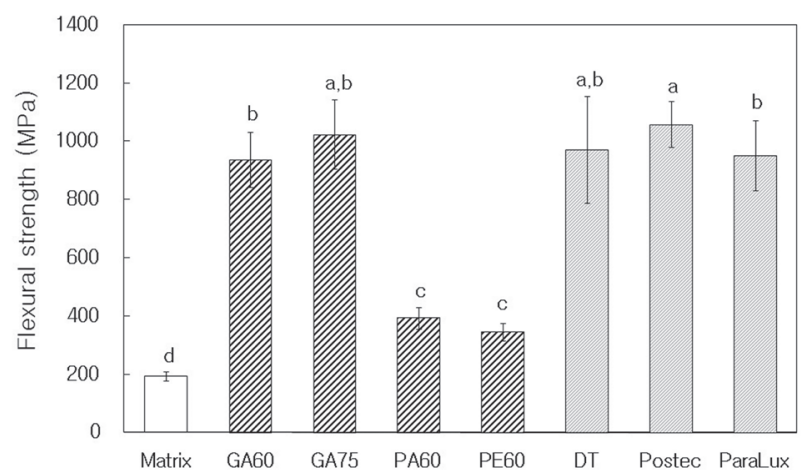

Fig. 2 Flexural strengths of the fabricated resin matrix, four experimental FRC posts (GA60, GA75, PA60, and PE60), and three commercial FRC posts (DT Light Post, FRC Postec Plus, and Parapost Fiber Lux).

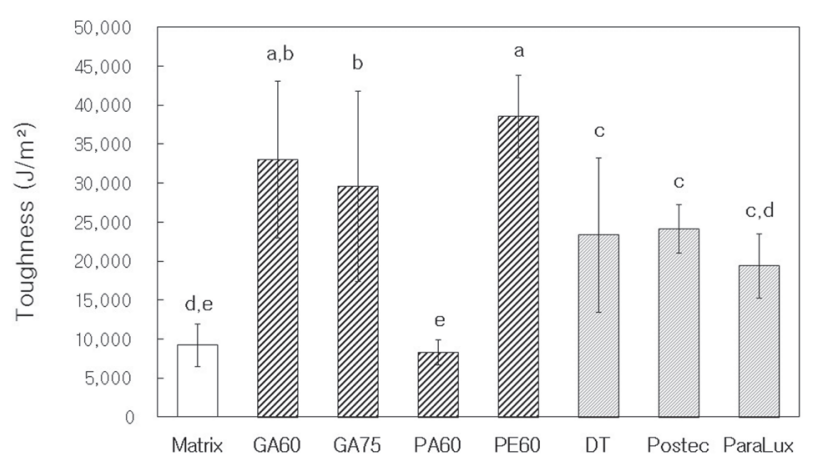

Fig. 4 Toughness of the fabricated resin matrix, four experimental FRC posts (GA60, GA75, PA60, and PE60) and three commercial FRC posts (DT Light Post, FRC Postec Plus, and Parapost Fiber Lux).

brittle, and its flexural modulus was between that of the GA and PE. It can be observed from Fig. 5 that the high ductility of $\mathrm{PE}$ is responsible for superior toughness, in spite of its low strength.

\section{SEM observation}

The longitudinal views of the experimental FRC posts after the flexural test showed a correlation with the flexural properties (Fig. 6). There was no bending in the GA post; however, cracks occurred with fractures of some fibers at the loading part (b). Severe distortion and bending occurred in the PE post with cracks only in the matrix, without the fracture of fibers (c, d). The amount of bending of the PA post (f) was between those of the GA and $\mathrm{PE}$ posts. In cross-sectional view, the $75 \% \mathrm{GA}$ post (a) appeared denser than the 60\% PE (c) and 60\% PA posts (e) due to its higher volume. The cross-sectional image of PE (c) seemed different from those of GA (a) and PA (e), because PE is not composed of single fiber strands, but woven structured fibers making up a $2 \mathrm{~mm}$ ribbond.

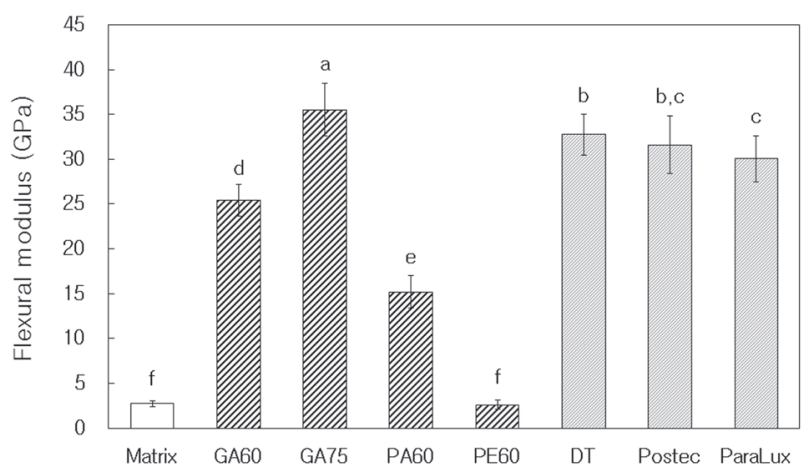

Fig. 3 Flexural moduli of the fabricated resin matrix, four experimental FRC posts (GA60, GA75, PA60, and PE60) and three commercial FRC posts (DT Light Post, FRC Postec Plus, and Parapost Fiber Lux).

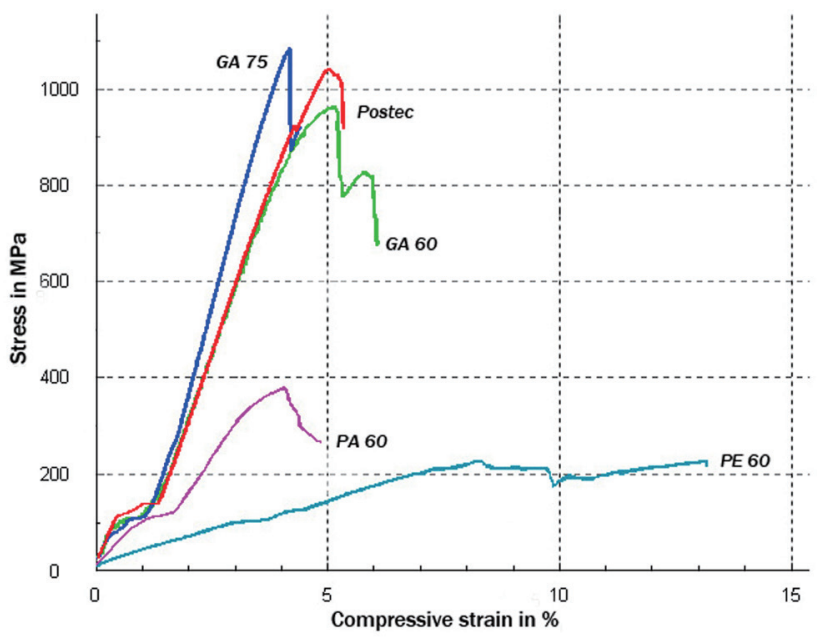

Fig. 5 Stress-strain curve of four experimental fiber posts (GA60, GA75, PA60 and PE60) and a commercial FRC post (FRC Postec Plus).

\section{DISCUSSION}

This study was undertaken to estimate the flexural properties of each experimental glass, aramid and UHMWP fiber post, and to compare them with various commercial FRC posts in order to evaluate their potential use as posts. The null hypothesis was rejected, because the flexural properties were significantly different depending upon the type of fibers used.

The flexural strengths of the experimental glass fiber posts were not significantly different from, and even higher than the commercial FRC posts in terms of toughness. The aramid and UHMWP posts showed significantly lower flexural strengths and moduli than the glass posts. However, the UHMWP posts resulted in higher toughness than the commercial FRC posts. The scanning electron microscopic images of the experimental 


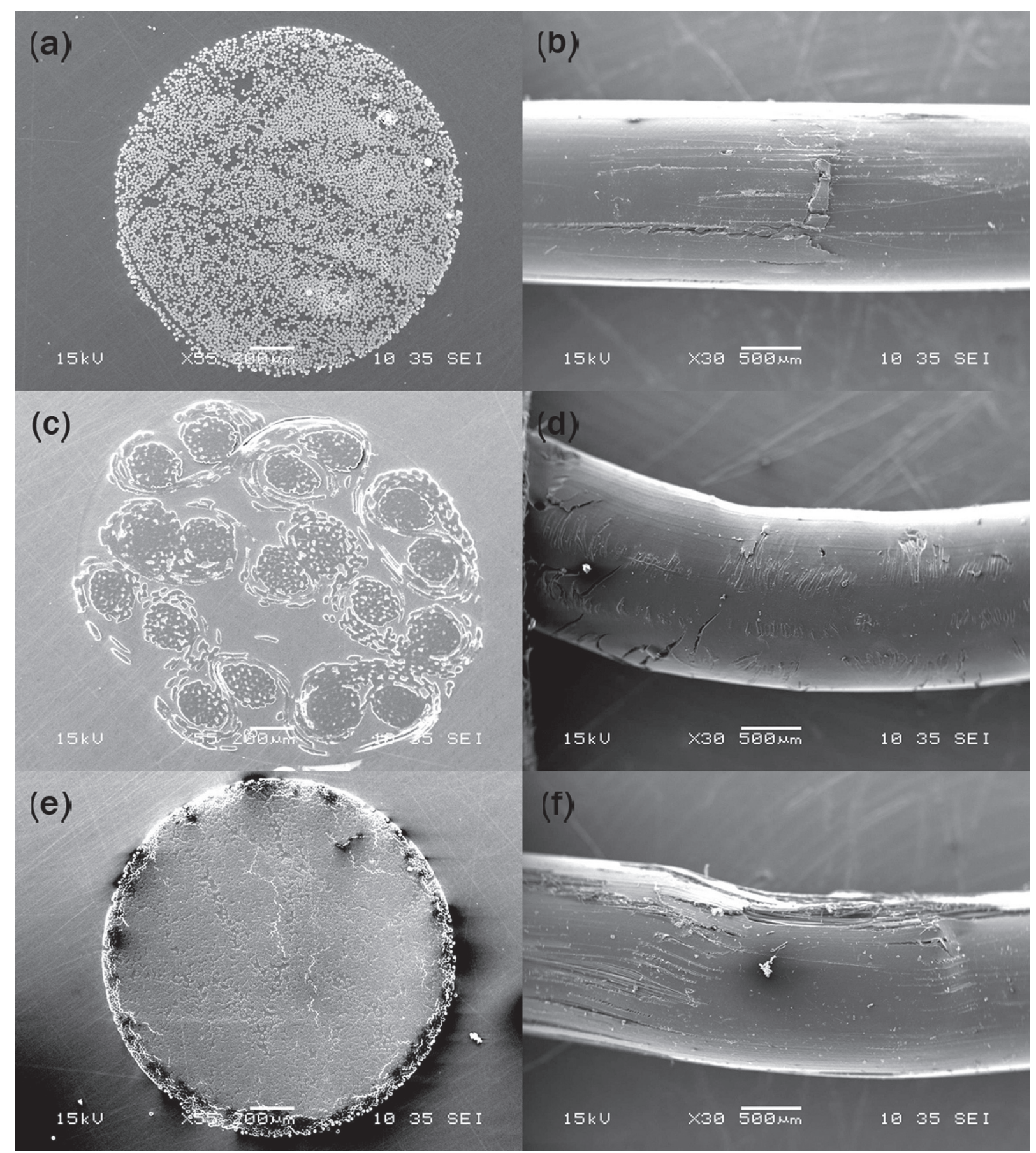

Fig. 6 Cross-sectional and longitudinal views of scanning electron microscopy of the GA75 (a), (b), PE60 (c), (d) and PA60 (e), (f), respectively.

posts also confirmed the results of flexural properties. From the results of the stress-strain curve, and the SEM observations, the characteristics of each experimental FRC post were differentiated. The GA post was stiff, strong, and brittle, while the PE post was flexible, weak, and ductile. The PA post was weak and brittle, and its flexural modulus was between that of the GA and PE. It can be estimated that the high ductility of $\mathrm{PE}$ is responsible for its superior toughness, in spite of its low strength. Toughness indicates the resistance of a material to fracture, and it is an indication of the amount of energy necessary to cause a fracture ${ }^{32,33)}$. When re-endodontic treatment is required, the post should ideally be removed from the root canal without fracture. Ceramic posts with low toughness are very problematic to retrieve, because the post is easily broken during the 
procedure ${ }^{3,12)}$. Posts with superior toughness would be advantageous in this regard. Although the flexural strengths and moduli of the UHMWP posts were lower than the glass posts, their superior toughness contributes to their importance as posts. In review, the aramid and UHMWP fibers showed a limitation when being used as posts alone, although reports exist regarding direct post build-up using UHMWP fibers ${ }^{20,34)}$. However, the superior toughness of the UHMWP posts suggests the potentiality of their being used as posts, in particular if used in combination with the glass fibers.

Unexpectedly, the experimental aramid fiber posts showed inferior flexural properties compared with glass posts. Previously, it was reported that the elastic moduli of aramid fibers were higher than those of glass and UHMWP fibers in a tensile mode ${ }^{14)}$. However, in the flexural mode of this study, the fiber orientation was perpendicular to the load application, while parallel in the tensile mode ${ }^{14)}$. In addition, Kevlar 29, an original type of aramid fiber, was used in this study. The flexural modulus could have been increased if Kevlar 49, a high modulus type, had been used. In this study, there was no surface treatment in the case of the aramid fiber. A method for treating the surface of organic fibers, especially for aramid fibers, should be established.

To elucidate the characteristics of experimental FRC posts more clearly, these posts were compared with various commercial FRC posts. In Fig. 5, the stressstrain curves of GA 75, Postec with $70 \%$ glass fibers, and GA 60 seem to be proportional to the amount of glass fibers in terms of flexural strength and modulus. The scanning electron microscopic images of the longitudinal and cross-sectional views of the experimental posts also confirmed the results of flexural properties, as well as the stress-strain curves. Superior toughness made the UHMWP post unbreakable, unlike the glass fiber posts. In Fig. 3, among the commercial FRC posts, the DT posts with $60 \%$ quartz fibers showed higher flexural modulus than the ParaLux posts with $60 \%$ glass fibers. Other studies also showed similar trends in concordance with these results ${ }^{24,35,36)}$.

Posts with higher mechanical properties do not guarantee a successful survival rate, because the posts do not strengthen teeth, rather, the preparation of a post space can weaken the root ${ }^{2,12)}$. The primary purpose of a post is to improve the retention of core materials in case of a significant loss of coronal tooth structure ${ }^{12)}$. Those posts with similar elastic modulus to dentin (17 GPa) resulted in a lower incidence of root fracture by acting as a monoblock with dentin ${ }^{3,32,37)}$. In this regard, FRC posts seem to have advantages over ceramic and metal posts. In addition, reports exist indicating that the fracture resistances of endodontically treated teeth restored with FRC posts were similar, or even higher than those restored with ceramic and titanium posts ${ }^{36,38,39)}$.

In this study, among the many factors related to the flexural properties of FRC, the components of the resin matrix and the fiber contents in experimental FRC posts were controlled. Three different experimental fiber posts showed distinct flexural properties, respectively.
Although glass fibers demonstrated the highest flexural strengths and moduli among the experimental posts, UHMWP fibers showed superior toughness. Within the limitations of this study, the aramid and UHMWP fibers are considered to have a limitation in their use as posts alone. However, UHMWP fibers exhibit the potential to be developed as new FRC posts by combining them with glass fibers, considering the superior toughness of UHMWP.

\section{CONCLUSIONS}

Within the limitation of this study, the following conclusions were drawn:

1. Among the experimental FRC posts, glass fiber posts showed significantly higher flexural strengths and moduli than aramid and UHMWP fiber posts $(p<0.05)$.

2. UHMWP posts resulted in superior toughness than commercial FRC posts $(p<0.05)$.

3. Glass fiber posts showed stiff, strong and brittle features, while UHMWP fiber posts were flexible, weak and ductile. The flexural properties of aramid fiber posts fell between those of glass and polyethylene.

The superior toughness of UHMWP suggests the possibility of its use as a post, if used in combination with glass fibers.

\section{ACKNOWLEDGMENTS}

The authors wish to thank the Hankuk Fiber Co., LTD (Milyang, Korea), and the Bisco Asia Co. (Seoul, Korea) for their donations of glass fibers and DT Light Post, respectively. This work was supported by the Korea Research Foundation Grant funded by the Korean Government (MOEHRD, Basic Research Promotion Fund) (KRF-2007-331-E00228).

\section{REFERENCES}

1) Jung SH, Min KS, Chang HS, Park SD, Kwon SN, Bae JM. Microleakage and fracture patterns of teeth restored with different posts under dynamic loading. J Prosthet Dent 2007; 98: 270-276.

2) Cheung W. A review of the management of endodontically treated teeth. J Am Dent Assoc 2005; 136: 611-619.

3) Richard SS, James WR. Post placement and restoration of endodontically treated teeth: a literature review. J Endod 2004; 30: 289-301.

4) Sadek FT, Monticelli F, Goracci C, Tay FR, Cardoso PEC, Ferrari M. Bond strength performance of different resin composites used as core materials around fiber posts. Dent Mater 2007; 23: 95-99.

5) Drummond JL, Toepke TR, King TJ. Thermal and cyclic loading of endodontic posts. Eur J Oral Sci 1999; 107: 220-224.

6) Mallmann A, Jacques LB, Valandro LF, Muench A. Microtensile bond strength of photoactivated and autopolymerized adhesive systems to root dentin using translucent and opaque fiber-reinforced composite posts. J Prosthet Dent 2007; 97: 165-172.

7) Bell AM, Lassila LV, Kangasniem I, Vallittu PK. Bonding of fibre-reinforced composite post to root canal dentin. J Dent 
2005; 33: 533-539.

8) Nagase DY, Takemoto S, Hattori M, Yoshinari M, Kawada E, Oda Y. Influence of fabrication techniques on retention force of fiber-reinforced composite posts. Dent Mater J 2005; 24: 280-285.

9) Mannocci F, Ferrari M, Watson TF. Intermittent loading of teeth restored using quartz fiber, carbon-quartz fiber, and zirconium dioxide ceramic root canal posts. J Adhesive Dent 1999; 2: 153-158.

10) Artopoulou II, O'Keefe KL, Powers JM. Effect of core diameter and surface treatment on the retention of resin composite cores to prefabricated endodontic posts. J Prosthodont 2006; 15: $172-179$

11) Butz F, Lennon AM, Heydecke G, Strub JR. Survival rate and fracture strength of endodontically treated maxillary incisors with moderate defects restored with different post-and-core systems: an in vitro study. Int J Prosthodont 2001; 14: 58-64.

12) Bitter $\mathrm{K}$, Priehn $\mathrm{K}$, Martus $\mathrm{P}$, Kielbassa AM. In vitro evaluation of push-out bond strengths of various luting agents to tooth-colored posts. J Prosthet Dent 2006; 95: 302-310.

13) Bae JM, Kim KN, Hattori M, Hasegawa K, Yoshinari M, Kawada E, Oda Y. Fatigue strengths of particulate filler composite reinforced with fibers. Dent Mater J 2004; 23: 166-174.

14) Bae JM, Kim KN, Hattori M, Hasegawa K, Yoshinari M, Kawada E, Oda Y. The flexural properties of fiber-reinforced composite with light-polymerized polymer matrix. Int $\mathrm{J}$ Prosthodont 2001; 14: 33-39.

15) Callister WD. In: Callister WD, editor. Materials science and engineering: an Introduction. 7th ed. Wiley Asia Student Ed. New York: John Wiley \& Sons; 2007. p. 585-615.

16) Mallick PK. In: Faulkner LL, editor. Fiber-reinforced composites. 2nd ed. New York: Marcel Dekker; 1993. p. 6-84.

17) Uzun G, Hersek N, Tinçer T. Effect of five woven fiber reinforcements on the impact and transverse strength of a denture base resin. J Prosthet Dent 1999; 81: 616-620.

18) Karaman AI, Kir N, Belli S. Four applications of reinforced polyethylene fiber material in orthodontic practice. Am J Orthod Dentofacial Orthop 2002; 121: 650-654.

19) Unlu N, Belli S. Three-year clinical evaluation of fiberreinforced composite fixed partial dentures using prefabricated pontics. J Adhes Dent 2006; 8: 183-188.

20) Deliperi S, Bardwell DN, Coiana C. Reconstruction of devital teeth using direct fiber-reinforced composite resins: a case report. J Adhes Dent 2005; 7: 165-171.

21) Dyer S, Lassila LVJ, Jokinen M, Vallittu PK. Effect of crosssectional design on the modulus of elasticity and durability of fiber-reinforced composite materials. J Prosthet Dent 2005; 94: $219-226$.

22) Drummond J, Bapna MS. Static and cyclic loading of fiberreinforced dental resin. Dent Mater 2003; 19: 226-231.

23) Heuman CCM, Kreulen CM, Bronkhorst EM, Lesaffre E, Creugers NHJ. Fiber-reinforced dental composites in beam testing. Dent Mater 2008; 24: 1435-1443.

24) Seefeld F, Wenz HJ, Ludwig K, Kern M. Resistance to fracture and structural characteristics of different fiber reinforced post systems. Dent Mater 2007; 23: 265-271.

25) Lastumäki TM, Lassila LVJ, Vallittue PK. The semiinterpenetrating polymer network matrix of fiber-reinforced composite and its effect on the surface adhesive properties. J Mater Sci Mater Med 2003; 14: 803-809.

26) Goracci C, Raffaelli O, Monticelli F, Balleri B, Bertelli E, Ferrari M. The adhesion between prefabricated FRC posts and composite resin cores: microtensile bond strength with and without post-silanization. Dent Mater 2005; 21: 437-444.

27) Garoughi S, Vallittu PK, Lassila LV. Use of short fiberreinforced composite with semi-interpenetrating polymer network matrix in fixed partial dentures. J Dent 2007; 35: 403-408

28) Bateman G, Ricketts DNJ, Saunders WP. Fibre-based post systems: a review. Br Dent J 2003; 195: 43-48.

29) Schmitter M, Huy C, Ohlmann B, Gabbert O, Gilde H, Rammelsberg P. Fracture resistance of upper and lower incisors restored with glass fiber reinforced posts. J Endod 2006; 32: 328-330.

30) Salameh Z, Sorrentino R, Papacchini F, Ounsi HF, Tashkandi E, Goracci C, Ferrari M. Fracture resistance and failure patterns of endodontically treated mandibular molars restored using resin composite with or without translucent glass fiber posts. J Endod 2006; 32: 752-755.

31) Vallittu PK. Ultra-high-modulus polyethylene ribbon as reinforcement for denture polymethyl methacrylate: A short communication. Dent Mater 1997; 13: 381-382.

32) Powers JM, Sakaguchi RL. In: Powers JM, Sakaguchi RL, editor. Craig's restorative dental materials. 12th ed. St. Louis: Elsevier; 2006. p. 55-69.

33) Karbhari VM, Strassler H. Effect of fiber architecture on flexural characteristics and fracture of fiber-reinforced dental composites. Dent Mater 2007; 23: 960-968.

34) Turker SB, Alkumru HN, Evren B. Prospective clinical trial of polyethylene fiber ribbon-reinforced, resin composite post-core buildup restorations. Int J Prosthodont 2007; 20: 55-56.

35) Galhano GA, Valandro LF, Melo RM, Scotti R, Bottino MA. Evaluation of the flexural strength of carbon fiber-, quartz fiber-, and glass fiber-based posts. J Endod 2005; 31: 209-211.

36) Akkayan B, Gülmez T. Resistance to fracture of endodontically treated teeth restored with different post systems. J Prosthet Dent 2002; 87: 431-437.

37) Tay FR, Pashley DH. Monoblocks in root canals: a hypothetical or a tangible goal. J Endod 2007; 33: 391-398.

38) Naumann M, Preuss A, Frankenberger R. Reinforcement effect of adhesively luted fiber reinforced composite versus titanium posts. Dent Mater 2007; 23: 138-144.

39) Rosentritt M, Sikora M, Behr M, Handel G. In vitro fracture resistance and marginal adaptation of metallic and toothcoloured post systems. J Oral Rehabil 2004; 31: 675-681. 